\title{
PREVALENCE OF VENOUS THROMBOEMBOLISM AMONG POST SCLEROTHERAPY PATIENTS
}

Ms. Smitha Sunny* | Dr. S. Rajina Rani**

* Research Scholar, Himalayan University, Itanagar in Arunachal Pradesh, India. **Research Supervisor, Himalayan University, Itanagar in Arunachal Pradesh, India. DOI: http://doi.org/10.47211/idcij.2021.v08i03.018

\section{ABSTRACT:}

Venous thrombo-embolism (VTE) is one of the most common and yet highly preventable cause of in-hospital death. VTE includes the manifestation of deep vein thrombosis and its fatal complication pulmonary embolism. To assess the development of VTE among post sclerotherapy patients, a descriptive retrospective research design was adopted. Random sampling technique was used to select 1000 post sclerotherapy patients who were undergone review for 3 months. The results depicted that most of the samples fell under the age group between 50 and 60 years, body mass index more than $25 \mathrm{Kg} / \mathrm{m}^{2}$ and majority were females. Only 5 samples were detected with symptoms of venous thromboembolism and were not having significant relationship with age, sex and body mass index.

Key words: Venous thromboembolism (pulmonary embolism and deep vein thrombosis), Post-sclerotherapy patients.

\section{ABOUT AUTHORS:}

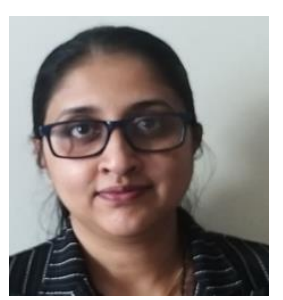

Author Ms. Smitha Sunny is a Research Scholar in Himalayan University, Itanagar in Arunachal Pradesh, India. She has attended various Seminars and conferences.

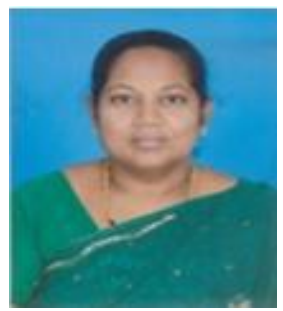

Author Dr. S. Rajina Rani is an active researcher with many publications in her name. She has attended and organised various National and International conferences and has given extensive lectures. At present she is research supervisor, Himalayan University, Itanagar in Arunachal Pradesh, India. 
INTRODUCTION:

\section{"Medicines are nothing in themselves if not properly used, but the very hands of God if employed with reason and prudence".}

- Herophilus

Venous thromboembolism (VTE) is a serious complication that is frequently encountered in medical and surgical practice. According to CDC, in U.S.A approximate 900,000 are affected with Venous thromboembolism with 100,000 deaths and burden with healthcare cost around 10 billion dollars. In England VTE (Venous Thromboembolism risk assessment was made compulsory from admission using national VTE risk assessment tool in order to curtail Hospital associated Venous thromboembolism morbidity and mortality. (Reyes, N. L. (2021).

Varicose veins are abnormally enlarged, elongated, tortuous superficial veins that may bulge from the surface of the skin and are usually seen in the legs. The condition is known as varicosity and to call an enlarged vein as varicose it needs to be larger than $3 \mathrm{~mm}$ in diameter. They can be dark purple or blue and remain harmless for quite a long time. Though most often seen on the inside of the leg and thigh they can be found in other parts of the body. Heredity is important in determining susceptibility to primary valvular failure, but the specific genetic factors responsible for varicosities have not yet been elucidated. Prolonged standing leads to increased hydrostatic pressures that can cause chronic venous distension and secondary valvular incompetence anywhere within the superficial venous system. Women are particularly susceptible to varicose disease because vein walls and valves periodically become more distensible under the influence of cyclic increases in progesterone. Pregnancy increases this susceptibility because circulating hormonal factors associated with pregnancy increase the dispensability of vein walls and softens valve leaflets. The prevalence rate of varicose veins is $43 \%$ in female relatives of patients with varicose veins, but only $19 \%$ in male relatives (Goldman, M. P., \& Weiss, R. A. (2016).

The venous system is a low-pressure high-volume system. Normally their valves allow blood to flow only inwards - from the superficial to the deep veins. The incompetence of these valves is the basic pathology of varicose veins. If the valves stop working properly, then blood is pushed out into the superficial veins when the muscles contract. This is one of the reasons for high pressure in the superficial veins and can be a cause of varicosity.

Venous thromboembolism (VTE) is a disease that includes both deep vein thrombosis (DVT) and pulmonary embolism (PE). It is a common, lethal disorder that affects hospitalized and non-hospitalized patients, recurs frequently, is often overlooked, and results in long-term complications including chronic thromboembolic pulmonary hypertension (CTPH) and the post-thrombotic syndrome (PTS)(Vedantham, S. (2008).

DVT and pulmonary embolism are the most serious potential complications after venous surgery, sclerotherapy, or endovenous procedures. Overspill of sclerosant into the deep system can cause DVT if the concentration of sclerosant is high enough to damage the endothelium of the deep veins. This is of particular concern when treating vessels in the knee and thigh, where the deep vessels in question (femoral and popliteal veins) are unpaired and thus without available collaterals (Sultan, A. A., Tata, L. J., West, J., Fiaschi, L., Fleming, K. M., Nelson-Piercy, C., \& Grainge, M. J. (2013).

Venous thromboembolism results from a combination of hereditary and acquired risk factors, also known as throm-bophilia or hypercoagulable states. In addition, vessel wall damage, venous stasis, and increased activation of clotting factors first described by Rudolf Virchow more than a century ago remain the fundamental basis for our understanding of thrombosis(Lewis, S. L., Bucher, L., Heitkemper, M. M., Harding, M. M., Kwong, J., \& Roberts, D. (2016).

Screening asymptomatic patients for DVT is labour intensive and cost ineffective. Thus, prophylaxis in at-risk populations remains the most effective means for preventing complications of VTE. For prophylaxis low dose of unfractionated heparin, low molecular weight heparin or warfarin can be prescribed depending on patient's level of risk and weight. (Lewis, S. L., Bucher, L., Heitkemper, M. M., Harding, M. M., Kwong, J., \& Roberts, D. (2016).

Sclerotherapy has been used as an alternative or an adjunct to surgery for treating varicose veins since the 1960s. It aims to prevent complications related to varicose veins, relieve symptoms, and improve leg appearance. The procedure involves directly injecting a chemical irritant (sclerosant) into the veins with a small needle. The sclerosant causes inflammation, thrombosis, and subsequent fibrosis of the vein.

\section{Statement of the problem}

"A study to assess the prevalence of venous thromboembolism among post sclerotherapy patients in a selected hospital in Kerala." 


\section{Objectives:}

1. To assess the prevalence of Venous thromboembolism among post sclerotherapy patients

2. To find the association of Venous thromboembolism with selected demographic variables

\section{METHODS AND MATERIALS:}

In view of nature of the problem selected for the study and the objectives to be accomplished, a descriptive retrospective survey was considered for present study. The sample for this study consisted of 1000 sclerotherapy patients in the year2012-2013. Randomized sampling technique was used to select patients who underwent 3-months review. A structured checklist was developed to assess the prevalence of venous thromboembolism and to identify the baseline data and the factors contributing venous thromboembolism among the selected post sclerotherapy patients. The checklist includes the assessment whether the post sclerotherapy patients developed VTE or not with or without any interventions. The checklist was also enabling to determine the personal characteristics which include age, sex, and Body mass index to find the factors contributing varicose vein and venous thromboembolism. The data were analysed using descriptive statistics. RESULTS:

\begin{tabular}{|l|l|l|l|l|l|l|}
\hline S.No. & $\begin{array}{l}\text { Demographic } \\
\text { variables }\end{array}$ & & Frequency & $\begin{array}{l}\text { Having } \\
\text { VTE }\end{array}$ & $\begin{array}{l}\text { Not having } \\
\text { VTE }\end{array}$ & Chi square \\
\hline 1 & Age & $\begin{array}{l}\text { Less than } \\
40\end{array}$ & 228 & 0 & 228 & $\begin{array}{l}0.580409 \\
\text { Not } \\
\text { Significant }\end{array}$ \\
\cline { 3 - 7 } & $\begin{array}{l}\text { More than } \\
40\end{array}$ & 772 & 5 & 767 & 0.095174 \\
\hline 2 & Sex & Male & 471 & 2 & 469 & $\begin{array}{l}\text { Not } \\
\text { Significant }\end{array}$ \\
\cline { 3 - 6 } & Female & 529 & 3 & 526 & $\begin{array}{l}1.174016 \\
\text { Not } \\
\text { Significant }\end{array}$ \\
\hline 3 & BMI & $\begin{array}{l}\text { Less than } \\
25\end{array}$ & 304 & 0 & 304 & $\begin{array}{l}2.6908 \\
\text { Not } \\
\text { Significant }\end{array}$ \\
\hline
\end{tabular}

\section{DISCUSSION:}

Venous thromboembolism (VTE) includes deep vein thrombosis (DVT) and pulmonary embolism (PE) is one of the serious complications associated with surgical procedures and it is associated with high health care costs (Heit, J. A. (2015). Since sclerotherapy is the obliteration of veins there is a chance of development of VTE. The purpose of the study is to identify the development of Venous Thromboembolism among sclerotherapy patients for the treatment of lower extremity varicose vein.

The subjects of this study constituted records of 1000 sclerotherapy patients. The mean age of the sample was $55+/-2.8$ and majority (26\%) of them fell under the age group mote than 40 years of age. Review of literature supports that venous thromboembolism increases with age. In a study conducted in U.S.A revealed that there is relationship between age and venous thromboembolism and this relationship is mainly depends on the procedure and the client's health status. According to American Heart Association (AHA) the Venous thromboembolism risk increases in patients more than 40 years of age and the risk doubles with subsequent decades (https://www.heart.org). In a retrospective study of post foam sclerotherapy patients, the mean age group of study participants were $50.7+/-0.86$ and8.3.7\% were females. The result highlights that VTE developed in $0.49 \%$ in a mean time of $44.4+/-42.2$ days. The study revealed that the incidence of Venous thromboembolism is low among post sclerotherapy patients and it is associated with male gender, family history of phlebitis or deep vein thrombosis and calibre of veins more $7 \mathrm{~mm}$ thick (de Aguiar, E. T., Dos Santos, J. B., \& Carvalho, D. D. (2021).

More than $70 \%$ of the sample collected for investigation reveals body mass index more than $25 \mathrm{Kg} / \mathrm{m} 2$. In another study it has been identified that obesity and smoking are the main factors for the development of VTE.(Holst, A. G., Jensen, G., \& Prescott, E. (2010).In a retrospective cohort study patients with deep vein thrombosis between 2008 and $2012,28 \%$ and $49 \%$ were over weight $\left(25-30 \mathrm{Kg} / \mathrm{m}^{2}\right)$ and obese (more than $25 \mathrm{~kg} / \mathrm{m}^{2}$ ). Even though the study highlights that obese patients have high frequency of deep vein thrombosis but paradoxically the mortality rate is high among non-obese patients. The mean age group is 50.3 and $51 \%$ were females (El-Menyar, A., Asim, M., \& Al-Thani, H. (2018). The association between obesity and VTE is 


\section{ARTICLES}

under investigation. In the present study the patients who developed signs of VTE belongs to the category of overweight $\left(25-30 \mathrm{Kg} / \mathrm{m}^{2}\right)$.

The present study did not show any association between sex and development of venous thromboembolism, but females were more prone to develop varicosities based on review of literature. (El-Menyar, A., Asim, M., \& Al-Thani, H. (2018).

As post-operative deep vein thrombosis is a known risk of invasive management of varicose vein, a retrospective analysis was conducted for a period of 10 year in 261,169 patients. 686 VTE cases were identified in 30 days, 884 at 90 days and 1264 at one-year period. An appreciable number can be detected for the patients undergoing different invasive procedure for the management of varicose vein, but very few with foam sclerotherapy. (Barker, T., Evison, F., Benson, R., \& Tiwari, A. (2017). It has been proved that the stratified incidence of venous thromboembolism in thermal ablation or foam sclerotherapy was low in as reported in both randomized controlled trials and case series investigation (Dermody, M., Schul, M. W., \& O’Donnell, T. F. (2015).

In the present study the investigator identified the development of Venous thromboembolism after the sclerotherapy was $1 \%$. The techniques modified microfoam sclerotherapy with usage of Polidacanol- the sclerosing agent and the post sclerotherapy management would resulted in the reduction in the development of Venous thromboembolism. Pharmacologic prophylaxis is safe and effective against VTE. Only 5 cases were detected before administration of inj. Fondaparinux which is cost-effective and has half life more than 17 hours. In addition, post sclerotherapy care includes elevation of the leg, compression and early ambulation helps to prevent complication. Foam sclerotherapy ensures high degree of safety with good technique, adequate imaging, general precautions and compliance with post-treatment instructions. The literature stated that only $1-3 \%$ of venous thromboembolism is associated with foam a sclerotherapy procedure which is similar to current study. (Cavezzi, A., \& Parsi, K. (2012).

The rising incidence of VTE across Asia may be attributable to aging population, dietary changes, and increasing incidence of obesity and diabetes as mentioned in The Asian venous thromboembolism (VTE) prophylaxis guidelines.(Liew, N. C., Alemany, G. V., Angchaisuksiri, P., Bang, S. M., Choi, G., DA, D. S., ... \& Lee, L. H. (2016).

\section{SUMMARY OF THE STUDY FINDINGS:}

1. The age group fell under $18-80$ years and $67 \%$ were in age group more than 40 years.

2. The body mass index of the sample ranges from $16 \mathrm{Kg} / \mathrm{m} 2-34 \mathrm{Kg} / \mathrm{m} 2$ and $70 \%$ were under the age group of body mass index more than $25 \mathrm{~kg} / \mathrm{m} 2$.

3. $53 \%$ of the samples were females.

4. Five cases of sample were detected with Venous thromboembolism and they were not received any preventive VTE prophylaxis

5. There is no association between the development of and selected variables like age, sex and body mass index.

6. The development of venous thromboembolism among post sclerotherapy patients depends on the type of the procedure, the sclerosing agent and the position maintained by the client.

\section{CONCLUSION:}

The study insisted the need for VTE prophylaxis in sclerotherapy patients irrespective of age, sex and BMI. Even though less than $1 \%$ of patients develop VTE, this can also be preventable. The study can be replicated on large samples to validate the findings and generalize. The data collection process enabled the investigator to deepen the awareness of various associated factors that contribute for the development of VTE in sclerotherapy patients. 


\section{ARTICLES}

\section{REFERENCES:}

1. Almodaimegh, H., Alfehaid, L., Alsuhebany, N., Bustami, R., Alharbi, S., Alkatheri, A., \&Albekairy, A. (2017). Awareness of venous thromboembolism and thromboprophylaxis among hospitalized patients: a cross-sectional study. Thrombosis Journal, 15(1), 1-8.

2. Nicholson, M., Chan, N., Bhagirath, V., \& Ginsberg, J. (2020). Prevention of venous thromboembolism in 2020 and beyond. Journal of Clinical Medicine, 9(8), 2467.

3. Barker, T., Evison, F., Benson, R., \& Tiwari, A. (2017). Risk of venous thromboembolism following surgical treatment of superficial venous incompetence. Vasa, 46(6), 484-489.

4. Dermody, M., Schul, M. W., \& O’Donnell, T. F. (2015). Thromboembolic complications of endovenous thermal ablation and foam sclerotherapy in the treatment of great saphenous vein insufficiency. Phlebology, 30(5), 357-364.

5. Cavezzi, A., \& Parsi, K. (2012). Complications of foam sclerotherapy. Phlebology, 27(1_suppl), 46-51.

6. Liew, N. C., Alemany, G. V., Angchaisuksiri, P., Bang, S. M., Choi, G., DA, D. S., ... \& Lee, L. H. (2016). Asian venous thromboembolism guidelines: updated recommendations for the prevention of venous thromboembolism. International angiology: a journal of the International Union of Angiology, 36(1), 1-20.

7. Beckman, M. G., Hooper, W. C., Critchley, S. E., \& Ortel, T. L. (2010). Venous thromboembolism: a public health concern. American journal of preventive medicine, 38(4), S495-S501.

8. Heit, J. A. (2015). Epidemiology of venous thromboembolism. Nature Reviews Cardiology, 12(8), 464474.

9. Goldman, M. P., \& Weiss, R. A. (2016). Sclerotherapy E-Book: Treatment of Varicose and Telangiectatic Leg Veins (Expert Consult). Elsevier Health Sciences. 